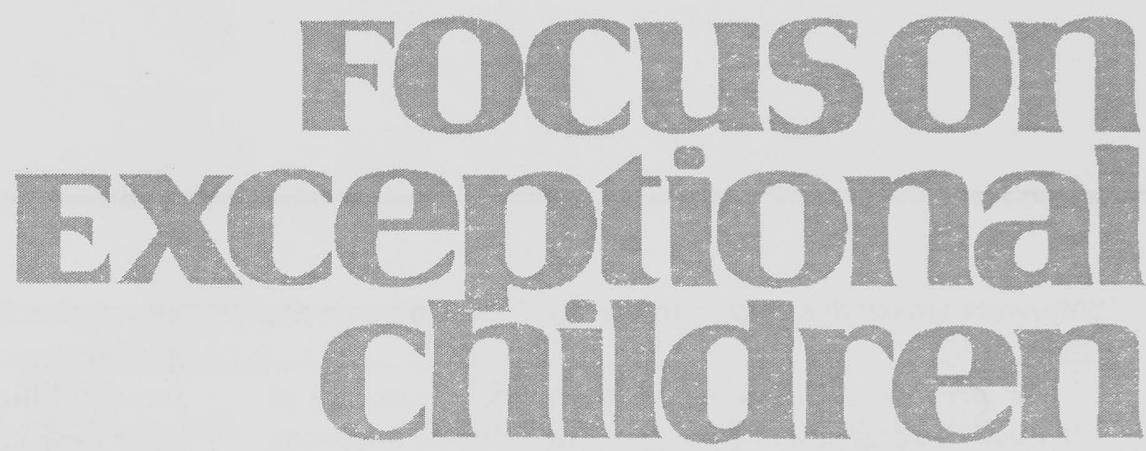

\title{
Reading Comprehension Instruction for Students with Learning Disabilities
}

\author{
Asha K. Jitendra and Meenakshi Gajria
}

Reading comprehension, which refers to "the process of simultaneously extracting and constructing meaning through interaction and involvement with written language" (Shanahan et al., 2010, p. 5) has garnered national attention through initiatives aimed at improving reading performance in schools (Reading First, No Child Left Behind Act [NCLB]). Many students, especially students with learning disabilities, experience persistent problems in comprehending text. These difficulties may not only be rooted in word recognition skills that are not automatic, but they may also stem from limited cognitive ability or problems with working memory, locating main ideas, inference making, flexibly selecting and applying strategies, and monitoring and evaluating strategy use (Gersten, Fuchs, Williams, \& Baker, 2001; Palincsar, David, Winn, \& Stevens, 1991; Rich \& Shepherd, 1993; Williams, 2004). Other factors such as insufficient prior knowledge, discrepant language experiences, or the lack of strategic skills may negatively influence comprehension (Armbruster, Anderson, \& Osterlag, 1987; Winograd, 1984). Specifically, students with learning disabilities (LD), who are often characterized as passive readers (Torgesen, 1982), either lack or seldom activate reading comprehension strategies to access information in textual material. Furthermore, they rarely monitor and evaluate their understanding of text.

According to the 2009 National Assessment of Educational Progress (NAEP), the percentage of fourth graders and eighth graders with disabilities who scored below the basic level in reading achievement was substantially higher (66\% and 63\%, respectively) than the percentage of fourth and eighth graders without disabilities (31\% and $22 \%$, respectively). That is, the majority of fourth graders and eighth graders with disabilities who participated in the NAEP did not understand grade-level text enough to get the gist of text. Although the advances made in designing effective decoding interventions are noteworthy, considerably less research addresses children's comprehension deficits not caused by decoding skill deficits or difficulties with lexical access (i.e., word finding abilities). In a synthesis of reading comprehension instruction for students with reading difficulties, Gersten et al. (2001) discussed the importance of comprehension strategies (single and multiple). Specifically, comprehension strategies should help "readers enhance their understanding, overcome difficulties in comprehending text, and compensate for weak or

\footnotetext{
Dr. Jitendra is a professor in the Special Education program, Department of Educational Psychology at the University of Minnesota. Dr. Gajria is a professor of education and chair of the Division of Teacher Education at St. Thomas Aquinas College.
} 
imperfect knowledge related to the text" (Shanahan et al., 2010, p. 10).

The purpose of this article is to provide a summary of effective comprehension strategies that focus on accessing knowledge to improve the comprehension skills of students with LD. We use Gajria, Jitendra, Sood, and Sacks' (2007) framework to organize comprehension strategies related to enhancing student mastery of specific content (i.e., text enhancement strategies) and teaching students how to learn and reflect (i.e., cognitive and metacognitive strategies) on their comprehension. In addition, we provide readers with assessment techniques to monitor student progress to inform reading comprehension instruction.

\section{TEXT ENHANCEMENT STRATEGIES}

Text enhancement strategies are approaches that teachers can use to effectively plan and deliver instruction to promote students' comprehension and retention of critical information (Lenz, Bulgren, \& Hudson, 1990). The underlying

\section{FOCuson Exceptional children}

ISSN 0015-511X

FOCUS ON EXCEPTIONAL CHILDREN (USPS 203-360) is published monthly except June, July, and August as a service to teachers, special educators, curriculum specialists, administrators, and those concerned with the special education of exceptional children. This publication is annotated and indexed by the ERIC Clearinghouse on Handicapped and Gifted Children for publication in the monthly Current Index to Journals in Education (CIJE) and the quarterly index, Exceptional Children Education Resources (ECER). The full text of Focus on Exceptional Children is also available in the electronic versions of the Education Index. It is also available in microfilm from Serials Acquisitions, National Archive Publishing Company, P.O. Box 998, Ann Arbor, MI 48106-0998. Subscription rates: individual, $\$ 50$ per year; institutions, \$68 per year. Copyright (C) 2011, Love Publishing Company. All rights reserved. Reproduction in whole or part without written permission is prohibited. Printed in the United States of America. Periodical postage is paid at Denver, Colorado. POSTMASTER: Send address changes to:

Love Publishing Company

Executive and Editorial Office P.O. Box 22353

Denver, Colorado 80222

Telephone (303) 221-7333

\section{CONSULTING EDITORS}

Steve Graham Vanderbilt University
Ron Nelson University of Nebraska-Lincoln

Eva Horn

University of Kansas

Carrie E. Watterson Senior Editor
Stanley F. Love Publisher assumption is that integration of instructional devices (e.g., graphic organizers) allows teachers to select, organize, and present difficult to understand material and make the text more meaningful and accessible to students of varying ability levels, including students with LD. Research indicates that instruction using graphic organizers and matrices that visually depict relationships between ideas (e.g., Bos \& Anders, 1990; DiCecco \& Gleason, 2002), advance organizers that prepare students for an upcoming lesson (e.g., Darch \& Gersten, 1986), story maps that emphasize story grammar elements in narrative texts, outlines and study guides that highlight critical information (e.g., Horton \& Lovitt, 1989), mnemonic illustrations that make the information more memorable (e.g., Mastropieri, Scruggs, \& Levin, 1987), and computer assisted instruction that provides opportunities for independent review and practice (e.g., Okolo \& Feretti, 1996) increase text comprehension and recall for students with $\mathrm{LD}$.

\section{Graphic Organizers}

Graphic organizers facilitate teaching and learning by visually representing the organization of key concepts, including their interrelationships, in a chapter or reading passage (Darch \& Eaves, 1986). Graphic organizers include semantic or cognitive maps, semantic feature analysis, and Venn diagrams. A key feature of graphic organizers is that they can be designed to represent different text structure patterns. For example, a web or hierarchical concept map can be used for a descriptive text structure, a flow chart for a cause-effect text structure, and a Venn diagram for a compare-contrast text structure. Figure 1 presents a sample of graphic organizers based on the five different types of expository text structures (Fisher, Frey, \& Lapp, 2009; Pearson \& Johnson, 1978) together with the associated clue words. The underlying rationale for these visual displays is that they help students develop a schema for how the content information is organized and provide them with a framework for connecting new information with their existing knowledge (Ausubel, 1963; Wittrock, 1992).

Integrating teacher or researcher constructed graphic organizers into content area instruction appears to be effective in promoting comprehension and retention of information from text. In a series of studies with high school students with $L D$, researchers documented the benefits of using semantic feature analysis, a relationship matrix that highlights major concepts and vocabulary from a passage (Anders, Bos, \& Filip, 1984; Bos, Anders, Filip, \& Jaffe, 1985, 1989). Students instructed using the matrix scored better than students in the comparison condition, who used a dictionary to define words and write a sentence for each word. Similarly, use of graphic organizers displaying relationships among ideas within a unit or chapter increased 


\begin{tabular}{lll}
\hline Text Structure & Word Signal \\
\hline Description & $\begin{array}{l}\text { To begin with, first, second, several, } \\
\text { numerous, for example, for instance, } \\
\text { most important, in fact, in addition }\end{array}$ \\
\hline $\begin{array}{l}\text { Temporal/Sequence/ } \\
\text { Chronological Order }\end{array}$ & $\begin{array}{l}\text { Next, first, second, then, originally, } \\
\text { finally, before, earlier, later, after, } \\
\text { following, soon, until, since, beginning, } \\
\text { during, eventually, numbers/letters } \\
\text { in parenthesis }\end{array}$ \\
\hline
\end{tabular}

TIME LINE

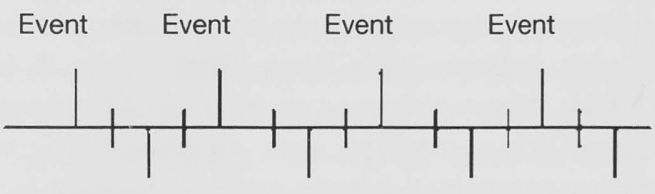

\begin{tabular}{ll}
\hline Compare and & Conversely, similarly, but, although, \\
Contrast & as well as, unlike, on the other hand, \\
on the contrary, nevertheless, whereas, \\
rather than
\end{tabular}

VENN DIAGRAM

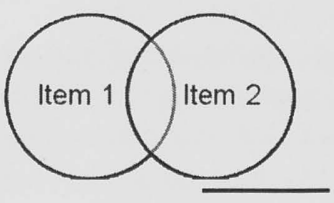

\begin{tabular}{|l|l|l|}
\hline \multicolumn{1}{c}{ MATRIX } \\
\begin{tabular}{|l|l|l|}
\hline & Item 1 & Item 2 \\
\hline Attribute 1 & & \\
\hline Attribute 2 & & \\
\hline Attribute 3 & & \\
\hline
\end{tabular}
\end{tabular}

Problem and Solution
As a result, because, so that, consequently, therefore, this led to, accordingly, thus

\section{PROBLEM SOLUTION FLOW CHART}

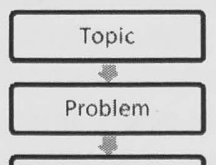

Possible Solution

Outcome

\section{Cause and Effect}

As a result, because, so that, consequently, therefore, this led to, accordingly, thus

\section{FISHBONE}

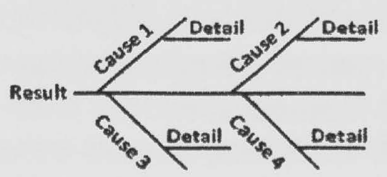

Source: Adapted from In a reading state of mind: Brain research, teacher modeling, and comprehension instruction (pp. 97-98), by D. Fisher, N. Frey, \& D. Lapp (2009), Newark, DE: International Reading Association. Copyright 2009 by International Reading Association. Reprinted with permission. 
comprehension performance for both high school students with LD (Darch \& Eaves, 1986; Darch \& Gersten, 1986) and students with LD in grades 4 through 6 (Darch \& Carnine, 1986; Griffin, Simmons, \& Kame'enui, 1991).

Using a different approach, DiCecco and Gleason (2002) studied the effectiveness of graphic organizers as a postreading rather than prereading activity on the social studies content knowledge of middle school students with LD. In addition to measuring factual comprehension using multiple-choice tests, they used written essays to assess relational content knowledge. Results indicated that the graphic organizer group outperformed students in the traditional instruction condition on relational content knowledge, but the two groups did not differ on factual content knowledge. It appears that graphic organizers can serve as retrieval cues and assist students in recall and organization of pertinent information. More recently, researchers documented the positive effect of using computerized graphic organizers with content area learning in inclusive classrooms (Boon, Burke, \& Fore, 2006; Boon, Burke, Fore, \& Hagan-Burke, 2006). When compared to traditional textbook instruction, instruction and review with computer-generated organizers (using Inspiration 6 software) significantly increased recall of social studies content on short essay recall questions for both students with and without disabilities.

Despite the different approaches employed, graphic organizers are effective instructional tools that facilitate comprehension for students with LD across content areas, particularly in social studies and science. In all the studies, the use of graphic organizers consistently resulted in significantly higher performance on researcher-developed multiple choice and free recall comprehension measures. However, in studies that assessed the long-term effects of the intervention, students did not maintain the gains or transfer effects to novel reading passages or standardized reading tests. This pattern of findings is consistent with other research showing that students with LD fail to spontaneously apply instructed strategies to new learning tasks (Gersten et al., 2001).

\section{Story Maps}

Story maps can be used to generate questions about narrative stories and as a prereading or postreading procedure to promote not only literal comprehension but also inferential thinking. The use of story maps has resulted in positive effects for improving the comprehension of both elementary and secondary students with LD (e.g., Boulineau, Fore, Hagan-Burke, \& Burke, 2004; Crabtree, Alber-Morgan, \& Konrad, 2010; Gardill \& Jitendra, 1999; Idol, 1987; Idol \& Croll, 1987; Taylor, Alber, \& Walker, 2002). Initial studies by Idol (1987) and Idol and Croll (1987) offered evidence of the effectiveness of using a simple story map (character, time, place, problem, goal, action, and outcome) to teach story grammar elements to elementary students with LD. At the completion of the intervention phase, the majority of students showed an increase in correct written responses to questions related to story grammar components. Further, the improved performance was maintained following completion of instruction. The success of the intervention was evident based on improved performance on standardized tests of reading comprehension.

In addition to use of story maps as visual displays of critical information in narrative texts, Crabtree et al. (2010) and Taylor et al. (2002) worked with high school and elementary students with LD, who were presented with a list of storyelement questions (e.g., Who are the main characters? What are the problems or conflicts?) embedded at specific stopping points as prompts to self-monitor their comprehension of story elements. At the completion of the intervention phase, story mapping and self-monitoring increased students' overall comprehension. Also encouraging are the results from studies of story mapping that indicate the maintenance effects of the strategy over time (e.g., Crabtree et al., 2010; Gardill \& Jitendra, 1999).

\section{Mnemonic Illustrations}

Given that many students with LD often experience problems memorizing abstract vocabulary and factual content, mnemonic illustrations are particularly useful in helping them acquire content area information (Scruggs, Mastropieri, McLoone, Levin, \& Morrison, 1987). Mnemonic devices facilitate learning by making unfamiliar, difficult to understand information more concrete, meaningful, and memorable by adding relevant connections and linking the information to students' existing knowledge base. Several researchers have studied the impact of textually embedded mnemonic illustrations on comprehension and recall of information. Illustrations are generally designed based on the keyword method, wherein a concrete, acoustically similar keyword is created for a new vocabulary term followed by an interactive illustration that demonstrates the meaning or definition of the term (Atkinson, 1975). The keyword method developed originally to facilitate acquisition of foreign-language vocabulary also appears to influence memory for factual information.

Scruggs et al. (1987) examined the effect of mnemonic illustrations based on the keyword method on the acquisition of science concepts with high school students with LD. Students read text about attributes of North American minerals, with either mnemonic or descriptive illustrations inserted into the passages. Results indicated that mnemonic illustrations substantially enhanced learning of dichotomized attributes of minerals. Similarly, Mastropieri et al. (1987) demonstrated that, compared with descriptive illustrations, 
mnemonic illustrations facilitated recall of expository reading passages that provided reasons, in decreasing order of their plausibility, for dinosaur extinction for middle school students with LD.

Subsequent studies on mnemonic illustrations in the area of social studies have reported similar findings. Brigham, Scruggs, and Mastropieri (1995) constructed maps displaying names of battles of the American Revolution and related battle information to teach history to middle school students with LD. The maps presented the information in the same format but used three different kinds of symbols: reconstructive elaborations of battle names, mnemonic keywords of battle names, and realistic drawings of soldiers and buildings. Mnemonic keywords resulted in higher recall of feature locations than traditional map symbols. However, recall did not differ significantly between the mnemonic and elaborative groups. Similarily, Mastropieri, Scruggs, and Whedon (1997) reported that keywords helped students remember significantly more US presidents than a traditional instruction condition. More recently, mnemonic illustrations did not positively impact social studies performance of students in inclusive high school classrooms, including students with LD (Fontana, Scruggs, \& Mastropieri, 2007). The authors attribute this finding to students in the study being higher functioning and using their own study strategies prior to and during the study. Overall, use of mnemonic illustrations that provide meaningful visual links and acoustic cues for encoding and retrieval is a promising approach for facilitating recall in the content areas, especially science and social studies.

\section{Study Guides}

Teachers can also improve reading comprehension by preparing study guides that direct students' attention to critical information in content area texts. Study guides typically consist of vocabulary terms, a series of statements, short answer questions, a chapter summary, or an outline based on the main concepts, and they can be integrated during or after instruction to support student learning. Lovitt and colleagues conducted several studies to determine the effect of study guides for facilitating text comprehension. Teacher directed study guides that sequenced the main ideas significantly increased comprehension of science content for seventh graders (Lovitt, Rudsit, Jenkins, Pious, \& Benedetti, 1986) and for high school students with LD (Bergerud, Lovitt, \& Horton, 1988). In both studies, students in the study guide condition outperformed students in the self-study condition. These findings were replicated using computerized study guides (Horton, Lovitt, Givens, \& Nelson, 1989) and hypertext study guides (Horton, Boone, \& Lovitt, 1990) for social studies content with high school students with LD. Study guides can also be successfully implemented in heterogeneous middle and high school classrooms to help students acquire information from content area texts (Horton \& Lovitt, 1989).

\section{Computer Assisted Instruction}

Use of computers and multimedia technology can incorporate critical instructional variables such as immediate feedback, correction, and self-pacing to enhance the presentation of instructional material and improve students' motivation and reading comprehension. Also, teachers can use computers to supplement instruction by providing students access to review, drill and practice exercises, and tutorials. Okolo and Ferretti (1996) examined the effects of integrating multimedia technology in project based learning in social studies with middle school students with LD. Students completed projects on the Revolutionary War using either word processing or multimedia presentation tools. Significant improvement in students' performance was noted on the knowledge test in both conditions, with no difference between the two groups; the authors attributed this finding to the similarity of activities in the two groups. Torgesen (1986) reviewed the research literature on computer assisted instruction specifically for students with LD and concluded that "computers have the capacity to deliver motivating, individualized practice in concentrations far beyond those available in traditional instruction" (p. 162).

Overall, research supports embedding text enhancements during instruction to promote reading comprehension and recall of narrative and expository texts for students with LD. Dependent on the content and learning objective, teachers can use different text enhancements to (a) select and present important information, (b) make abstract information more meaningful, (c) visually represent the relationships between concepts, (d) direct students' attention to pertinent information, (e) individualize instruction, (f) provide memory cues to facilitate recall, and $(\mathrm{g})$ make the information load more manageable for students. Consistently positive effects were noted for use of various text enhancements-graphic organizers, story maps, mnemonic illustrations, study guides, and computer assisted instruction.

\section{COGNITIVE AND METACOGNITIVE STRATEGIES}

According to Rosenshine (1995), a cognitive strategy is "a heuristic or guide that serves to support or facilitate the learner as she or he develops the internal procedures that enable them to perform the higher level operations [such as reading comprehension]" (p. 266). Cognitive strategies, single or multiple, have been shown to help students with LD learn from text. Single strategies reported in the literature include recognizing text structure, cognitive mapping, questioning, identifying main ideas, and summarization. Multiple 
strategies develop different kinds of thinking and include Reciprocal Teaching and its variants such as Collaborative Strategic Reading (CSR) and POSSE (Predict, Organize, Search, Summarize, Evaluate), as well as SQ3R (Survey, Question, Read, Recite, Review). Even though these strategies cultivate different comprehension skills, they include several common goals and components. First, a common goal of the different cognitive strategies is to teach students how to interact with the content so that learning becomes more deliberate, self-directed, and self-regulated. Second, all cognitive strategies require the student to read the text, ask questions, draw connections, find main ideas, clarify meaning, reread, and paraphrase or summarize key information. A third component is that the instructional method (direct instruction) used in cognitive strategy training emphasizes effective principles of instructional design (e.g., clear description of the strategy, teacher modeling, corrective feedback, guided and independent practice). In contrast, metacognition is the ability to think about and reflect on one's thinking. Students with LD often have difficulty thinking about whether they understand what they are reading and do not know how or when to use strategies that will help them understand what they are reading. Therefore, instruction in metacognition or metacognitive skillfulness- "the procedural knowledge to actually use metacognition" (Martini \& Shore, 2008, p. 243)-is an important consideration for students with LD to use comprehension strategies independently.

\section{Text Structure}

Teaching students to identify a text's organizational structure is critical for comprehending and remembering content, because awareness of text structure can aid in extracting and constructing meaning while reading (Shanahan et al., 2010). It is important for students to recognize the distinction between the two genres (narrative and informational) of text structure as they use them to "build their understanding and recall of key points" (p. 17). For instance, understanding that narrative texts (e.g., historical fiction, fables, autobiographies) typically tell a story depicting a sequence of events that involve characters helps students to "distinguish between major and minor events and predict how a story might unfold" (p. 17). Informational texts, in contrast, consist of expository writing (e.g., news articles, speeches) and "communicate information so that the reader might learn something" (Weaver \& Kintsch, 1991/1996, p. 230).

\section{Narrative Texts}

Story grammar (or story schema) represents the structure of narrative texts. The structural elements (story grammar) common to most narrative texts include, for example, the setting, characters, goal, problem, plot or action, resolution, and a theme (Baumann \& Bergeron, 1993; Morrow, 1996; and Pressley et al., 1990). Given that students with LD do not have as well developed a sense of story grammar as their nondisabled peers and often have trouble recalling elements of a story, particularly the more abstract elements such as theme and resolution, several interventions have focused on teaching story grammar to improve their reading comprehension. Specifically, these studies have shown that directly teaching story grammar can highlight important relations, which, in turn, leads to a deeper understanding of the story. Using advanced reading material (i.e., literature), for example, Dimino, Gersten, Carnine, and Blake (1990) directly taught an interactive comprehension strategy based on story grammar that provided opportunities for secondary students, including students with LD, to "clarify and discuss important elements of the story as they read" (p. 29). The complex stories involved detailed character information (clues and reaction), the presence of more than one problem that may require several attempts, a resolution, a complication or a twist, and a theme. Students who received the intervention showed greater gains in comprehension compared to students who were not exposed to the intervention. Although the success of this intervention for students with LD is not clear, given that results were not disaggregated for students with LD, the study by Gurney, Gersten, Dimino, and Carnine (1990) using a similar approach provided evidence that these students' comprehension of important elements in literature anthologies can be improved as a function of story grammar instruction.

Story grammar interventions that emphasized metacognition (recognizing when and how to apply the story grammar strategy) seem to improve students' reading comprehension (Carnine \& Kinder, 1985; Faggella-Luby, Schumaker, \& Deschler, 2007; Griffey, Zigmond, \& Leinhart, 1988; Therrien, Wickstrom, \& Jones, 2006). The study conducted by Carnine and Kinder (1985) with upper elementary students with LD indicated that directly teaching them how to ask questions about story elements improved their comprehension. Although the study by Griffey et al. (1988) found that story grammar intervention alone or used along with a selfmonitoring strategy showed modest pretest to posttest gains for students with LD in grades 3 through 5, it did not lead to better comprehension than teaching students to question themselves about the text. It appears that the four sessions of instruction in this study may not have been sufficient for students with LD, who often need more time to realize gains in reading comprehension.

More recently, the use of story grammar instruction along with question generation (Therrien et al., 2006) and selfquestioning before reading (Faggella-Luby et al., 2007) have been found to be effective in improving the reading 
comprehension performance of students with LD. Over a 4month period, Therrien et al. (2006) successfully taught students with LD in grades 4 through 8 how to use a cue card with generic story structure questions to answer factual and inferential questions. Faggella-Luby et al. (2007) examined the effectiveness of an Embedded Story Structure (ESS) Routine, an intervention that incorporated effective components of instruction (e.g., advance organizer, modeling, corrective feedback) and essential story elements with high school students with LD. The success of the intervention in improving student comprehension may be attributed not only to the careful design of the intervention but also to the intensive instruction (17 hours) that students received.

\section{Informational Texts}

Informational texts have a variety of text structures (e.g., compare-contrast, sequence, cause-effect, description) that can be challenging for students with LD. As such, teachers can selectively provide instruction on common informational text structures (e.g., compare-contrast). At the same time, it is critical that "teachers use familiar ideas or topics when teaching students about the structure of informational text, and initially use texts that provide clear, easy-to-recognize examples of the structure" (Shanahan et al., 2010, p. 19). For instance, a teacher could model a compare-contrast text on pilgrims and Native Americans or different types of rocks and have the students make a table or diagram to depict the similarities and differences. Smith and Friend (1986), for example, conducted a study that taught high school students with LD to recognize and use five different text structures (time-order, problem/solution, comparison, description, and cause-effect) to guide their comprehension of expository prose. Following the intervention, students could recognize the different text structures and recall the main ideas. Similarly, Bakken, Mastropieri, and Scruggs (1997) used a text structure based strategy to teach eighthgrade students with LD to identify three kinds of text structures (i.e., main idea, list, and order) in science passages and apply structure specific strategies to study passages. The intervention not only resulted in improved performance on recall measures but also led to transfer to untrained social studies passages. Therefore, it is encouraging that text structure-based strategies can be successfully taught to students with $\mathrm{LD}$ to improve their comprehension.

\section{Cognitive Mapping/Story Mapping}

Students with LD are not as likely as their peers to identify and visually represent main ideas that are known to facilitate comprehension. As such, teaching these students a cognitive mapping or story mapping strategy can help them visualize what is described in the text. In two separate studies conducted by Boyle (1996, 2000), middle and high school students with LD and those with mild cognitive disabilities were taught to independently construct cognitive maps (including a Venn diagram, a specific type of cognitive map to compare and contrast main ideas) from reading passages. Using a mnemonic, students were prompted to identify and link the main ideas with the supporting details. Following the intervention, students in the study by Boyle (1996) who were exposed to the cognitive mapping strategy showed improvements in both literal and inferential comprehension skills. However, this success did not transfer to performance on a standardized reading comprehension assessment. In contrast, students in the later Boyle (2000) study improved on measures of literal comprehension and relational comprehension more than they improved on inferential comprehension. It appears that teaching students to use cognitive maps is useful when the details and relationships in the diagrams are made explicit.

Recall that cognitive strategies teach students how to interact with the content so that learning becomes more deliberate, self-directed, and self-regulated in contrast to text enhancements that allow teachers to select, organize, and present difficult to understand material and make the text more meaningful and accessible. As such, the story mapping intervention in the well-designed study conducted by Johnson, Graham, and Harris (1997) would be deemed a cognitive strategy, because it focused on students constructing their own story map using story grammar elements. In this study, all students with LD in grades 4 through 6 made gains following the completion of the intervention (story mapping strategy only, with goal-setting, with self-instruction, with both goal-setting and self-instruction); however, students who received story mapping with both goal setting and self-instruction improved the most in story grammar recall. Students with LD whose performance was far below that of their nondisabled peers prior to the intervention improved such that their performance following the intervention was comparable.

\section{Questioning}

This approach is known to promote comprehension by teaching students how to activate prior knowledge, summarize text, and check their understanding of the material (Mastropieri, Scruggs, Bakken, \& Whedon, 1996). A questioning strategy that taught students to ask themselves questions as they interacted with the text to find main ideas, generate related questions, and monitor understanding of textual units has been shown to be effective for enhancing the comprehension performance of eighthand ninth-grade students with LD (Wong \& Jones, 1982). Another effective questioning approach is the Question Answer Relationships (QARs) strategy that has been used to help students in grades 1 through 9 to comprehend 
information in social studies text (Simmonds, 1992). In this approach, students learn to differentiate among three kinds of comprehension questions, 'Right There' (literal question), 'Think and Search' (text implicit-text-based inference question) and 'On My Own' (script implicitprior knowledge-based inference question). Such an approach would allow students to draw inferences from information in text that is missing or not explicitly stated (Shanahan et al., 2010).

The use of elaborative interrogation is another helpful comprehension-building strategy that Mastropieri, Scruggs, Hamilton, et al. (1996) have used to teach seventh- and eighth-grade students to actively reason through the information in prose passages containing science facts by questioning each science fact and generating an explanation for it. When compared to traditional instruction, the elaborative interrogation strategy significantly increased student provided explanations for the facts but not recall of facts. Questioning strategies that facilitate critical thinking skills are also important to cultivate for students with LD. Darch and Kame'enui (1987), for example, conducted a study in which they directly taught fourth to sixth grade students with LD to detect invalid arguments in texts. They were taught three specific skills: detect faulty generalizations, detect false causality, and detect invalid testimonials. At the completion of the intervention, the effect size comparing students who were taught critical thinking skills to students who were not exposed to this approach were large on a measure that assessed knowledge of three critical reading skills (argument analysis, embedded argument analysis, skill classification). However, the effects were not realized on a reading comprehension measure.

\section{Main Idea Instruction}

According to Williams (1988), the ability to find the main idea is "the basis for being able to draw appropriate inferences from the text, to study effectively, and to read critically" (p. 2). In other words, getting the main idea from a text is central to reading comprehension (van den Broek, Lynch, Naslund, Ievers-Landis, \& Verduin, 2003). It is important to note that the nature of the main idea differs between narrative and expository text types (see Baumann, 1986; Moore, Cunningham, Rudisill, 1983; Pearson \& Johnson, 1978). In narrative texts, the reader has to discern the theme of a story from the description of events and their temporal sequence. In contrast, expository text requires the reader to develop a generalization or a thesis based on the logical relationship of ideas about a topic. Given the different genres within expository prose (e.g., description, compare-contrast, sequence, cause-effect, problem-solution), the main idea or what is important may be defined by a specific genre (Williams, 1988, 2004).
Students with LD frequently struggle with identifying the main idea in reading passages, and the challenge is more pronounced with content area texts. Several researchers have successfully used direct instruction principles of teacher modeling, guided practice, and corrective feedback to help students identify or construct the main idea of texts. Jenkins, Heliotis, Stein, and Haynes (1987) taught elementary school students with LD to restate the most important idea for each paragraph in a narrative. To generate a restatement, students learned to ask themselves two questions, "who" the paragraph was about and "what's happening." Results supported the usefulness of writing restatements of important ideas to improve reading comprehension.

Other studies that focused on a paraphrasing or restatement strategy combined with self-questioning procedures also produced similar results. Ellis and Graves (1990) taught upper elementary and middle school (grades 5-7) students to ask themselves, "What is the main idea of the paragraph?" and to state the main ideas in prose passages in their own words. In comparison to repeated reading procedures, paraphrasing instruction resulted in improved comprehension and maintenance of strategy effects. Wong and Jones (1982) taught students with LD in grades 8 and 9 a selfquestioning approach to interact with the text to come up with "a paraphrased version of the main idea" (p. 231). Following the training, student comprehension improved, especially in terms of increased awareness of important textual units and ability to generate questions related to those units. In the Bakken et al. (1997) study, eighth-grade students who were taught to apply a paragraph restatement strategy to science passages involving three types of text structures (main idea, list, order) improved their performance on immediate and delayed recall measures, and they transferred the strategy to social studies.

Researchers have also combined principles of direct instruction with self-monitoring procedures to teach main ideas with considerable success. Graves (1986) compared two approaches to main idea instruction-direct instruction and direct instruction plus self-monitoring. Students in grades 5 through 8 were taught a rule to find main ideas ("a main idea tells what the whole story is about," p. 94). Students in the direct instruction and self-monitoring group were taught to stop twice during reading, to self-question their understanding of the main idea, and to place a check mark on a self-monitoring card. Results indicated improvement in both groups' comprehension performance in comparison to a control condition; the self-monitoring component had an added value in increasing comprehension of main ideas. In a related study, Graves and Levin (1989) documented that self-monitoring of main ideas was more effective than a mnemonic condition for discerning main ideas in 
texts. Similarly, Jitendra, Cole, Hoppes, and Wilson (1998) affirmed the positive effects of direct instruction and selfmonitoring for identifying main ideas in passages for three 6th-grade students with LD.

In essence, research supports main idea instruction using principles of direct instruction combined with self-questioning or self-monitoring procedures to increase comprehension skills. Main idea instruction resulted in improved outcomes on comprehension measures on both narrative and expository texts for students with LD in grades 5 through 9 . Additionally, in some studies, main idea instruction resulted in maintenance and transfer.

\section{Summarization}

Summarization training that emphasizes the "structure of ideas within text and how individual ideas relate to each other" (Rinehart, Stahl, \& Erikson, 1986, p. 424) is likely to lead to greater recall and retention of text. Summarizing requires students to draw upon their prior knowledge to perform a series of cognitive operations on the information that is read: evaluate to determine whether the information is important enough to include in a summary, condense to combine important idea units, and transform to present the gist in "their own words." The greater attention to text during summarization results in students more closely monitoring and evaluating their reading to comprehend text. As a consequence, summarization training has a reciprocal effect on improving "students' metacognitive control of the reading process" (p. 424). The goal of summarization training should make students aware of the highest level of information or main ideas in a text as well as details that support the main ideas, because both are critical to remember for school success.

Many studies have examined the value of summarizing as a comprehension strategy. Gajria and Salvia (1992) used a direct instruction approach to teach students with LD in grades 6 through 9 to develop a summary or gist of the main ideas of a passage by applying the five rules proposed by Brown and Day. (1983): reduce lists, select topic sentences, construct topic sentences, delete redundancies, and delete unimportant information. After each rule was mastered in isolation, students received instruction and guided practice in the combined use of the rules. Figure 2 presents a prompt sheet used for instruction in a summarization strategy. Gradually, students assumed increasing responsibility for applying the rules to construct passage summaries. Instruction results were positive: Students taught to summarize outperformed students in the comparison condition on comprehension measures, maintained the skill, and demonstrated gains on the comprehension subtest of the Gates-MacGinitie, a standardized reading assessment. Similar positive effects of explicit instruction in rule-governed summary skills were documented on comprehension of science text for five students with LD in grades 4 through 8 (Nelson, Smith, \& Dodd, 1992).

Different from the rule-governed approach to summary instruction, Malone and Mastropieri (1992) instructed middle school students with LD to ask questions about the subject of each paragraph and the related action and to use the information to write a summary sentence. Students were also taught to use a self-monitoring card to check application of the strategy. Students in both groups, summarization and summarization with self-monitoring, outperformed students in the self-study group on reading comprehension measures. Students also trained in the self-monitoring component successfully transferred the strategy from narrative to social studies passages. Similarly, Jitendra, Hoppes, and Xin (2000) assessed the effectiveness of combining selfmonitoring with a summarization strategy. Middle school students were taught to identify and generate main idea sentences that summarized the passage in addition to using a self-monitoring procedure for comprehension. Results indicated that instruction resulted in improved comprehension performance, which was maintained 6 weeks after training. Further, transfer effects to novel passages were found on selection items, but the effects were less robust on production of responses, possibly as a result of a higher readability level and more implicit idea units in the transfer passages as compared to the training passages.

The studies by Gajria and Salvia (1992), Jitendra et al. (2000), Malone and Mastropieri (1992), and Nelson et al. (1992), are of great importance because they facilitated the construction of meaning from text by teaching summarization skills rather than simply identifying main ideas. As summarization is a complex skill that students do not use naturally while reading, explicit instruction in summarization, preferably with a self-monitoring component, is essential. Summarization instruction enhanced students' ability to effectively summarize both narrative and expository text and resulted in improved comprehension and recall, with robust maintenance and transfer effects.

\section{Multiple strategy instruction}

As Shanahan et al. (2010) noted, "multiple-strategy instruction might be more complicated initially, but it familiarizes students with using the strategies together from the very beginning, providing a more authentic, strategic reading experience" (p. 13). Based on research with students with LD, reciprocal teaching and its variants are key examples of multiple-strategy formats that combine various strategies. Another multiple strategy approach involves verbal rehearsal strategies such as SQ3R (Survey, Question, Read, Recite, Review) and its adaptations (e.g., multipass strategy). 


\section{General Steps to Form a Summary}

- Understand the passage - First, read the title to help you know what the passage is about. Then, read the passage slowly and ask yourself, "What is the general idea of this passage? What is the writer telling in this passage?" Try to say the general idea in your own words.

- Check the passage - Reread the passage to make sure you got the general theme. Then, apply the five summarization rules.

\section{Rules for Writing a Summary}

1. Reduce lists - If you come across a list of things in a passage, try to think of a word or a phrase that best describes the list of things. For example, if a list of items includes apples, peaches, grapes, plums, and strawberries, you could categorize the items in this list as fruits. Underline the list of items and write the category name for the list of items in the passage.

2. Cross out repeated information - Sometimes, information in a passage may be repeated. That is, the same thing may be said again in a different way in the same passage. So, keep one sentence and get rid of the repeated statements by crossing them out with a red pen.

3. Select a topic sentence - Often authors write a sentence that gives the main idea of the passage. This is called a topic sentence. It is often the first sentence or last sentence in the paragraph. Read once again each paragraph of the passage. Try to say the main idea of each paragraph to yourself. Next, search for the topic sentence in the paragraph. If the author gives the topic sentence, underline it, and say it in your own words.

4. Write your own topic sentence - Sometimes the author does not write a topic sentence for a paragraph. Make up your own topic sentence for each paragraph that does not have one. Write your topic sentence in the margin. Use your topic sentences in your summary.

5. Cross out unimportant details - Sometimes passages contain unimportant or unnecessary details that do not deal directly with the general theme of a passage. Get rid of this information. Cross out unimportant sentences with a blue pen.

\section{Check Your Work}

- Have you underlined all lists in the passage and written a category name for each list?

- Do you have a topic sentence for each paragraph?

- Did you cross out information that is repeated?

- Did you cross out information that is not important?

- Have you applied the five rules to each paragraph in the passage?

Now use your marked passage to write a summary. Use connecting words (e.g., "and," "so," "or") to join sentences. You can also join the paragraphs together. Try to say the information in your own words.

Source: From "Main Idea and Summarization Instruction to Improve Reading Comprehension" (p. 213), by A. K. Jitendra, \& M. Gajria (2011) in R. O’Connor and P. Vadasy (Eds.), The Handbook of Reading Interventions. New York: Guilford Press.

\section{FIGURE 2. Prompt Sheet for Summarization Instruction}

\section{Reciprocal Teaching}

Developed by Palincsar and Brown (1986), reciprocal teaching that consists of four strategies-predicting, clarifying, questioning, and summarizing - helps students to build on and monitor their own comprehension. In this approach, students in small groups take turns assuming the role of the teacher and leading a discussion of the text using the four strategies that are first modeled by the teacher. As such, peer mediation and student discourse are used to scaffold instruction for students with LD. The findings of two studies that examined the effectiveness of reciprocal teaching for students with LD are mixed. On the Gates-MacGinite standardized reading subtest, middle school students with LD trained in summarizing, questioning, clarifying, and predicting in the study by Labercane and Battle (1987) did 
not perform any better than students who did not receive instruction in the four strategies. In contrast, elementary school students, including students with LD in grades 4 to 6 inclusive classrooms, who received the strategy instruction in the study conducted by Lederer (2000) performed better than their counterparts who did not receive such instruction in answering short questions, generating questions, and composing summaries. One plausible explanation for the contradictory results may be attributed to the different measures (distal or proximal to the intervention) used to assess comprehension.

Variations of reciprocal teaching have been used in some studies with considerable success. For example, collaborative strategic reading (CSR), an adaptation of reciprocal teaching includes four strategies: preview, click and clunk, get the gist, and wrap up. Students are taught to apply these strategies before reading (i.e., preview by connecting the topic with what is already known and predict what will be learned about the topic), during reading (e.g., monitor comprehension and use fix-up strategies to decipher unknown words or phrases [referred to as the click and clunk strategy] and identify the most important ideas in the text to get the gist) and after reading (wrap up-generate questions and review key ideas learned). Klingner, Vaughn, Arguelles, Hughes, and Leftwich (2004) successfully used CSR to teach fourth grade students with LD to learn from social studies text. Students who received instruction in the four strategies made greater gains in reading comprehension than students who received traditional instruction in the same content.

Using reciprocal teaching formats (i.e., extensive teacher modeling of strategies followed by a gradual transfer of strategy control to students), Englert and Mariage (1991) taught upper elementary students with LD several strategies cued by the acronym POSSE (Predict, Organize, Search, Summarize, and Evaluate). Prereading strategies in the POSSE instruction were predicting (i.e., activating background knowledge) and organizing ideas based on text structure, whereas the remaining three strategies (search and summarize main ideas based on text structure, evaluate comprehension) were during-reading strategies. Researchers developed several materials to scaffold student learning. For example, a strategy sheet was used "to make visible to students both the strategies and the text structures for performing the reading process" (p. 126), and cue cards were used "to prompt the self-talk and inner language related to a particular reading strategy, such as predicting, organizing, searching, summarizing, and evaluating" (p. 127). This well-designed intervention led to students using the POSSE strategy outperforming students who received traditional instruction in the same text on all comprehension measures: total free recall of ideas, recall of main ideas, overall organization of recalls, and strategy knowledge.

\section{$S Q 3 R$}

The use of verbal rehearsal strategies is helpful in improving students' reading comprehension competence. With this learning strategy approach, the teacher first describes and models each strategy, followed by students rehearsing orally and practicing implementing each strategy using selected texts, and finally the teacher provides feedback to students. McCormick and Cooper (1991), for example, conducted a study in which they directly taught secondary students with LD to use SQ3R, which prompted students to survey the text for clues, ask text-related questions, read the text to find answers, paraphrase (recite) the answers found in the text, and review the information in the text. Across a series of three studies, the effects of SQ3R were not found for literal comprehension as measured by retelling. However, the percentages of retelling were strongly related to the length of the text read, with higher percentages of recall found for shorter than longer passages.

It must be noted that an adaptation of SQ3R, Multipass (survey, size-up, and sort-out), produced robust effects on content tests for secondary students with LD using instructional level texts (Schumaker, Deshler, Alley, Warner, \& Denton, 1982). The strategies were used to (a) familiarize students with the main ideas and organization of the chapter (survey), (b) gain specific information from the text without reading the entire text (size-up), and (c) have students test themselves on the material in the text (sort-out). Following the implementation of Multipass, students were also able to generalize their strategy use on grade-level materials.

In sum, research supports instruction in cognitive and metacognitive strategies for students with LD. For both narrative and informational texts, instruction in a specific strategy or a combination of strategies-awareness of text structure, cognitive mapping, questioning, main ideas, and summarization-consistently resulted in improved comprehension performance. Though less frequently, long-term maintenance and transfer of strategy effects were also noted. Strategy instruction helps students with LD to be more purposeful in their reading, to actively interact with the text, determine the author's message, construct meaning, and monitor their own understanding-efficient reading processes demonstrated by strategic readers. For effective strategy instruction, it appears that not only use of clear descriptions of the strategy and teacher modeling followed by student verbal rehearsal, practice, and extensive feedback is critical, but also selecting instructional level texts is necessary to enhance reading comprehension for students with $\mathrm{LD}$.

\section{ASSESSMENT OF READING COMPREHENSION}

Reading comprehension assessment should focus on helping students learn and helping teachers teach. As such, 
we discuss assessment in terms of monitoring student progress in meeting lesson objectives and long-term goals and making instructional decisions (e.g., planning tasks to foster student understanding). Assessment tasks that provide teachers and students with ongoing feedback concerning their progress in the reading curriculum should be based primarily on the classroom reading materials. Measuring students' general comprehension to make instructional decisions would require collecting data frequently using a variety of topics, texts (e.g., textbooks, anthologies, tradebooks), and tasks (Taylor, Harris, Pearson, \& Garcia, 1995). To assess general comprehension, assessment tasks should not only focus on the product (right or wrong response) but also on the reading comprehension process (e.g., how students are thinking or using and developing ideas).

In general, making judgments about students' comprehension of specific material requires first assessing their background knowledge of the reading material. The extent of students' background knowledge (high, moderate, low) can differentially influence comprehension of material to be read. Questions are the most common techniques used to assess comprehension. However, good questions should be framed to focus on important ideas rather than trivial details. Given that many students with LD have difficulty with free response questions, timed assessment, and written responses, these are factors that should be considered when using questions to assess these students' reading comprehension. When evaluating students' ability to comprehend narrative or expository text, it is important to use instructional level text. Alternatives to asking students questions based on the text to assess their comprehension might include having students generate questions, choose the best questions among a set of choices, or select the best summary of a narrative or expository material from among several choices. In addition, assessment tasks should focus on evaluating students' literal and inferential comprehension using the QARs approach described earlier with both narrative and expository text written at the students' instructional level. Finally, students' inference processing ability when reading can be assessed using probing questions. Such questions would allow the teacher to delve deeper into students' initial answers by asking them to explain how they conceptualized the particular answers or asking students why one answer might be better than another from several possible answers provided (Taylor et al., 1995). The information generated from such questioning would enable the teacher to understand and evaluate a student's inferencing ability (e.g., answers text-based inference question or "think and search" QAR, but unable to answer "on my own" QAR) and provide the necessary support to improve their comprehension.

In addition to the questioning approach, asking students to retell a story (oral or written) is an important means of assessing comprehension. Using the story map as a guide, a teacher can determine whether the student can concisely describe important information related to the main character, setting, conflicts, key events, resolution, and theme, if any might be present or inferred. Further, assessment tasks should determine whether students can proceed from identifying or generating main ideas in expository paragraphs to summarizing important ideas in longer passages of content area texts written at the students' instructional level. The assessment tasks may include having students list a topic and write the main idea sentence for each of several sections of a text or summarize a few important ideas for a section (e.g., a page) of the text rather than stating the main idea for each paragraph in the section. Summaries can be scored for the important ideas and supporting details expressed as opposed to trivial details. Figure 3 presents a rubric that teachers can use to evaluate students' summaries.

Although understanding students' comprehension is important, it is equally critical to assess students' metacognitive awareness related to use of comprehension strategies. The assessment, therefore, should determine the extent to which students understand the text they are reading (i.e., the clicks and clunks of comprehension), are able to detect their sources of comprehension difficulty, and use appropriate fix-up strategies to resolve comprehension problems (Taylor et al., 1995). Tools to assess students' ability to monitor and control their comprehension process may include questionnaires (e.g., When you are reading and do not understand the text, what do you do? What do you do to help you remember what you have read?), observations, interviews, or thinkalouds (Taylor et al., 1995).

\section{CONCLUSION}

For teachers working with students with LD, there appears to be some guidance for providing remedial reading comprehension instruction. The increased emphasis not only on "scientifically-based research," but also "adequate yearly progress" as it relates to NCLB has led to systematic inquiry into the type of strategies that enhance text comprehension and assessment to monitor student progress in the instructional materials. Developing the comprehension skills of students with LD requires that instruction focus on both text enhancement strategies as well as cognitive and metacognitive strategies.

In general, the evidence suggests that text enhancements such as graphic organizers, story maps, mnemonic illustrations, and study guides are promising instructional devices that teachers can integrate in a lesson to scaffold student learning. Text enhancements make the learning material more concrete and meaningful and thereby engage students with LD who often struggle to access information independently 


\begin{tabular}{llll}
\hline Indicator & Below Standard & Approaching Standard & At Standard \\
\hline Complete & Included one or two facts & $\begin{array}{l}\text { Partial summary with some } \\
\text { important ideas, a few facts }\end{array}$ & $\begin{array}{l}\text { Adept summary with most } \\
\text { ideas, details, facts, and } \\
\text { important vocabulary }\end{array}$ \\
Correct & $\begin{array}{l}\text { Main idea is not expressed; } \\
\text { it may include incorrect } \\
\text { information }\end{array}$ & $\begin{array}{l}\text { Main idea is partially } \\
\text { expressed; it may include } \\
\text { misinterpretation }\end{array}$ & $\begin{array}{l}\text { Main idea is clearly } \\
\text { expressed; all facts included } \\
\text { are correct }\end{array}$ \\
Precise & $\begin{array}{l}\text { Included extra unimportant } \\
\text { details; repeated ideas }\end{array}$ & $\begin{array}{l}\text { Included some extra } \\
\text { unimportant details, or } \\
\text { repeated few ideas }\end{array}$ & $\begin{array}{l}\text { No unimportant details } \\
\text { included; ideas not repeated }\end{array}$ \\
Quality of Writing & $\begin{array}{l}\text { Generally written as } \\
\text { "copied text" with some } \\
\text { own words }\end{array}$ & $\begin{array}{l}\text { Generally written in own } \\
\text { a list of disconnected ideas }\end{array}$ & $\begin{array}{l}\text { Written in own words, } \\
\text { flows smothly from one } \\
\text { idea to another }\end{array}$ \\
\hline $\begin{array}{l}\text { Source: Adapted from Comprehension shouldn't be silent: From strategy instruction to student independence (p. 161), by M. } \\
\text { J., Kelley \& N. Clausen-Grace (2007), Newark, DE: International Reading Association. }\end{array}$ &
\end{tabular}

\section{FIGURE 3. Summarizing Rubric}

from teacher lecture or texts. In contrast to text enhancements that address students' acquisition and mastery of specific content information, the focus of instruction in cognitive and metacognitive strategies is on teaching students how to learn. Explicit instruction in a single cognitive strategy (e.g., main idea, questioning, summarizing) or an integrated combination of strategies (e.g., reciprocal teaching, SQ3R) can help students with LD acquire reading processes proven effective across content areas. Continued use of cognitive strategies helps students with LD transition from passive readers to self-directed readers who actively engage with the lecture or text to construct meaning and improve performance on classroom-based and standardized comprehension assessments.

\section{REFERENCES}

Atkinson, R. C., (1975). Mnemotechnics in second language learning. American Psychologist, 30, 821-828.

Anders, P. L., Bos, C. S., \& Filip, D. (1984). The effect of semantic feature analysis on the reading comprehension of learning disabled students. In J. A. Niles \& L. A. Harris (Eds.), Changing perspectives on reading/language processing and instruction ( $\mathrm{pp}$. 162-166). Rochester, NY: National Reading Conference.

Armbruster, B. B., Anderson, T. H., \& Ostertag, J. (1987). Does text structure/summarization instruction facilitate learning from an expository text? Reading Research Quarterly, 22, 331-336.

Ausubel, D. P. (1963). The psychology of meaningful verb learning. New York: Grune \& Stratton.
Bakken, J. P., Mastropieri, M. A., \& Scruggs, T. E. (1997). Reading comprehension of expository science material and students with learning disabilities: A comparison of strategies. The Journal of Special Education, 31, 300-324.

Baumann, J. F. (1986). Teaching main idea comprehension. Newark, DE: International Reading Association.

Baumann, J. F., \& Bergeron, B. S. (1993). Story map instruction using children's literature: Effects on first graders' comprehension of central narrative elements. Journal Reading Behavior, 25, 407-437.

Bergerud, D., Lovitt, T. C., \& Horton, S. (1988). The effectiveness of textbook adaptations in life science for high school students with learning disabilities. Journal of Learning Disabilities, 21, 70-76.

Boon, R. T., Burke, M. D., \& Fore, C, III. (2006). The impact of cognitive organizers and technology-based practices on student success in secondary social studies classrooms. Journal of Special Education Technology, 21(1), 5-15.

Boon, R. T., Burke, M. D., Fore, C., \& Hagan-Burke, S. (2006). Improving student content knowledge in inclusive social studies classrooms using technology-based cognitive organizers: A systematic replication. Learning Disabilities: A Contemporary Journal, 4, 1-17.

Bos, C. S., \& Anders, P. L. (1990). Effects of interactive vocabulary instruction on the vocabulary learning and reading comprehension of junior-high learning disabled students. Learning Disability Quarterly, 13, 31-42.

Bos, C. S., Anders, P. L., Filip, D., \& Jaffe, L. E. (1985). Semantic feature analysis and long-term learning. In J.A. Niles \& R.V. Lalik (Eds.), Issues in literacy: A research perspective. (pp. 42-47). Rochester, NY: National Reading Conference.

Bos, C. S., Anders, P. L., Filip, D., \& Jaffe, L. E. (1989). Effects of an interactive instructional strategy for enhancing reading comprehension and content learning for students with learning disabilities. Journal of Learning Disabilities, 22, 384-390. 
Boulineau, R. T., Fore, C., Hagan-Burke, S., \& Burke, M. D. (2004). Use of story-mapping to increase the story-grammar text comprehension of elementary students with learning disabilities. Learning Disabilities Quarterly, 27, 105-121.

Boyle, J. R. (1996). The effects of a cognitive mapping strategy on the literal and inferential comprehension of students with mild disabilities. Learning Disability Quarterly, 19, 86-98.

Boyle, J. R. (2000). The effects of a Venn diagram strategy on the literal, inferential, and relational comprehension of students with mild disabilities. Learning Disabilities: A Multidisciplinary Journal, 10(1), 5-13.

Brigham, F. J., Scruggs, T. E. \& Mastropieri, M. A. (1995). Elaborative maps for enhanced learning of historical information: uniting spatial, verbal, and imaginable information. The Journal of Special Education, 28, 440-460.

Brown, A. L., \& Day, J. D. (1983). Macrorules for summarizing texts: The development of expertise. Journal of Verbal Learning and Verbal Behavior, 22, 1-14.

Carnine, D., \& Kinder, B. D. (1985). Teaching low performing students to apply generative and schema strategies to narrative and expository material. Remedial and Special Education, 6, 20-30.

Crabtree, T., Alber-Morgan, S. R., Konrad, M. (2010). The effects of self monitoring of story elements on the reading comprehension of high school seniors with learning disabilities. Education \& Treatment of Children, 33, 187-203.

Darch, C., \& Carnine, D. (1986). Teaching content area material to learning disabled students. Exceptional Children, 53, 240-246.

Darch, C., \& Eaves, R. (1986). Visual displays to increase comprehension of high school learning-disabled students. Journal of Special Education, 20, 309-318.

Darch, C., \& Gersten, R. (1986). Direction-setting activities in reading comprehension: A comparison of two approaches. Learning Disability Quarterly, 9, 235-243.

Darch, C., \& Kame'enui, E. J. (1987). Teaching LD students critical reading skills: A systematic replication. Learning Disability Quarterly, 10, 82-91.

DiCecco, V. M., \& Gleason, M. M. (2002). Using graphic organizers to attain relational knowledge from expository text. Journal of Learning Disabilities, 35, 306-320.

Dimino, J., Gersten, R., Carnine, D., \& Blake, G. (1990). Story grammar: An approach for promoting at-risk secondary students' comprehension of literature. The Elementary School Journal, 91, 19-32.

Ellis, E. S., \& Graves, A. W. (1990) Teaching students with learning disabilities: A paraphrasing strategy to increase comprehension of main ideas. Rural Special Education Quarterly, 10(2), 2-10.

Englert, C. S., \& Mariage, T. V. (1991). Making students partners in the comprehension process: Organizing the reading "POSSE." Learning Disability Quarterly, 14, 123-138.

Faggella-Luby, M., Schumaker, J., \& Deschler, D. (2007). Embedded learning strategy instruction: Story-structure pedagogy in heterogeneous secondary literature classes. Learning Disability Quarterly, 30, 131-147.

Fisher, D., Frey, N., \& Lapp, D. (2009). In a reading state of mind: Brain research, teacher modeling, and comprehension instruction. Newark, DE: International Reading Association.

Fontana, J. K., Scruggs, T. E., \& Mastropieri, M. A. (2007). Mnemonic strategy instruction in inclusive social studies classes. Remedial and Special Education, 28, 345-355.

Gajria, M., Jitendra, A. K., Sood, S., \& Sacks, G. (2007). Improving comprehension of expository text in students with LD: A research synthesis. Journal of Learning Disabilities, 40, 210-225.
Gajria, M., \& Salvia, J. (1992). The effects of summarization instruction on text comprehension of students with learning disabilities. Exceptional Children, 58, 508-516.

Gardill, M. C., \& Jitendra, A. K. (1999). Advanced story map instruction: Effects on reading comprehension of students with learning disabilities. The Journal of Special Education, 33, 2-17.

Gersten, R., Fuchs, L. S., Williams, J. P., \& Baker, S. (2001). Teaching reading comprehension strategies to students with learning disabilities: A review of research. Review of Educational Research, $71,279-320$

Graves, A. W. (1986). Effects of direct instruction and metacomprehension training on finding main ideas. Learning Disabilities Research, 1(2), 92-100.

Graves, A. W., \& Levin, J. R. (1989). Comparison of monitoring and mnemonic text-processing strategies in learning disabled students. Learning Disability Quarterly, 12, 232-236.

Griffey, Q. L., Jr., Zigmond, N., \& Leinhart, G. (1988). The effects of self-questioning and story structure training on the reading comprehension of poor readers. Learning Disabilities Research, 4(1), $45-51$.

Griffin, C. C., Simmons, D. C., \& Kame'enui, E. J. (1991). Investigating the effectiveness of graphic organizers instruction on the comprehension and recall of science content by students with learning disabilities. Reading, Writing, and Learning Disabilities, 7, 355-376.

Gurney, D., Gersten, R., Dimino, J., \& Carnine, D. (1990). Story Grammar: Effective literature instruction for high school students with learning disabilities. Journal of Learning Disabilities, 23, $335-342$

Horton, S. V., Boone, R. A., \& Lovitt, T. C. (1990). Teaching social studies to learning disabled high school students: Effects of a hypertext study guide. British Journal of Educational Technology, $21,118-131$

Horton, S. V., \& Lovitt, T. C. (1989). Using study guides with three classifications of secondary students. The Journal of Special Education, 22, 447-462.

Horton, S. V., Lovitt, T. C., Givens, A., \& Nelson, R. (1989). Teaching social studies to high school students with academic handicaps in a mainstream setting: Effects of a computerized study guide. Journal of Learning Disabilities, 22, 102-107.

Idol, L. (1987). Group story mapping: A comprehension strategy for both skilled and unskilled readers. Journal of Learning Disabilities, 20, 196-205.

Idol, L., \& Croll, V. J. (1987). Story-mapping training as a means of improving reading comprehension. Learning Disability Quarterly, 10, 214-229.

Jenkins, J. R., Heliotis, J. D., Stein, M. L., \& Haynes, M. C. (1987). Improving reading comprehension by using paragraph restatements. Exceptional Children, 54, 54-59.

Jitendra, A. K., Cole, C. L., Hoppes, M. K., \& Wilson, B. (1998). Effects of a direct instruction main idea summarization program and self-monitoring on reading comprehension of middle school students with learning disabilities. Reading and Writing Quarterly, 14(4), 379-396.

Jitendra, A. K., Hoppes, M. K., \& Xin, Y. P. (2000). Enhancing main idea comprehension for students with learning problems: The role of a summarization strategy and self-monitoring instruction. Journal of Special Education, 34, 127-139.

Jitendra, A. K., \& Gajria, M. (2011). Main idea and summarization instruction to improve reading comprehension. In R. O'Connor 
and P. Vadasy (Eds.), The handbook of reading interventions. New York: Guilford Press.

Johnson, L., Graham, S., \& Harris, K. R. (1997). The effects of goal setting and self-instructions on learning a reading comprehension strategy: A study with students with learning disabilities. Journal of Learning Disabilities, 30, 80-91.

Kelley, M. J., \& Clausen-Grace, N. (2007). Comprehension shouldn't be silent: From strategy instruction to student independence. Newark, DE: International Reading Association.

Klingner, J. K., Vaughn, S., Arguelles, M. E., Hughes, M. T., \& Leftwich, S. A. (2004). Collabrative strategic reading: "Real-world" lessons from classroom teachers. Remedial and Special Education, 25, 291-302.

Labercane, G., \& Battle, J. (1987). Cognitive processing strategies, self-esteem, and reading comprehension of learning disabled students. B.C. Journal of Special Education, 11(2), 167-185.

Lederer, J. M. (2000). Reciprocal teaching of social studies in inclusive elementary classrooms. Journal of Learning Disabilities, 33, 91-106.

Lenz, B. K., Bulgren, J. A., \& Hudson, P. (1990). Content enhancement: A model for promoting the acquisition of content by individuals with learning disabilities. In T. E. Scruggs \& B. L. Y. Wong (Eds.), Intervention research in learning disabilities (pp. 122-165). New York: Springer-Verlag.

Lovitt, T., Rudsit, J., Jenkins, J., Pious, C., \& Benedetti, D. (1986). Adapting science materials for regular and learning disabled seventh graders. Remedial and Special Education, 7, 31-39.

Martini, R., \& Shore, B. M. (2008). Pointing to parallels in ability-related differences in the use of metacognition in academic and psychomotor tasks. Learning and Individual Differences, 18 , 237-247.

Malone, L. D., \& Mastropieri, M. A. (1992). Reading comprehension instruction: summarization and self-monitoring training for students with learning disabilities. Exceptional Children, 58, 270-279.

Mastropieri, M. A., Scruggs, T. E., Bakken, J.P., \& Whedon, C. (1996). Reading comprehension: A synthesis of research in learning disabilities. In T. E. Scruggs \& M. A. Mastropieri (Eds.), Advances in learning and behavioral disabilities: Intervention research. (Vol. 10, Part B, pp. 201-227). Greenwich, CT: JAI.

Mastropieri, M. A., Scruggs, T. E., Hamilton, L. S., Wolfe, S., Whedon, C., \& Canevaro, A. (1996). Promoting thinking skills of students with learning disabilities: effects on recall and comprehension of expository prose. Exceptionality, 6(1), 1-11.

Mastropieri, M. A., Scruggs, T. E., \& Levin, J. R. (1987). Learning disabled students' memory for expository prose: Mnemonic versus nonmnemoni pictures. American Education Research Journal, 24, $505-519$.

Mastropieri, M. A., Scruggs, T. E., \& Whedon, C. (1997). Using mnemonic strategies to teach information about U.S. presidents: A classroom-based investigation. Learning Disability Quarterly, 20, 13-20.

McCormick, S., \& Cooper, J. O. (1991). Can SQ3R facilitate learning disabled students' literal comprehension of expository text? Three experiments. Reading Psychology, 12, 239-271.

Moore, D. W., Cunningham, J. W., \& Rudisill, N. J. (1983). Readers' conceptions of the main idea. In J. A. Niles and L. A. Harris (Eds.), Searches for meaning in reading/language processing and instruction (pp. 202-206). Thirty-second yearbook of the National Reading Conference. Rochester, NY: National Reading Conference.
Morrow, L. M. (1996). Motivationg readings and writing in diverse classrooms: Social and physical contexts in a literature-based program (NCTE Research Report no. 28). Urbana, IL: National Council of Teachers of English.

Nelson, J. R., Smith D. J., \& Dodd, J. M. (1992). The effects of teaching a summary skills strategy to students identified as learning disabled on their comprehension of science text. Education and Treatment of Children, 15, 228-243.

Okolo, C. M., \& Ferretti, R. P. (1996). Knowledge acquisition and technology supported projects in the social studies for students with learning disabilities. Journal of Special Education Technology, 13, 91-103.

Palincsar, A. S., \& Brown, A. L. (1986). Interactive teaching to promote independent learning from text. The Reading Teacher, 39, 771-777.

Palinscar, A., David, Y., Winn, J., \& Stevens, D. (1991). Enhancing the content of strategy instruction. Remedial and Special Education, $12,43-53$.

Pearson, P. D., \& Johnson, D. D., (1978). Teaching reading comprehension (2nd ed.). New York: Holt, Rinehart, \& Winston.

Pressley, M., Burkell, J., Cariglia, T., Lysynchuk, L., McGoldrick, J. A., Schneider B., et al. (1990). Cognitive strategy instruction that really improves children's academic performance. Cambridge, MA: Brookline Books.

Rich, R., \& Shepherd, M. J. (1993). Teaching text comprehension strategies to adult poor readers. Reading and Writing: An Interdisciplinary Journal, 5, 387-402.

Rinehart, S. D., Stahl, S. A., \& Erickson, L. G. (1986). Some effects of summarization training on reading and studying. Reading Research Quarterly, 21, 422-438.

Rosenshine, B. (1995). Advances in research on instruction. Journal of Educational Research, 88, 262-268.

Scruggs, T. E., Mastropieri, M. A., McLoone, B. B., Levin, J. R., \& Morrison, C. R. (1987). Mnemonic facilitation of learning disabled students' memory for expository prose. Journal of Educational Psychology, 79, 27-34.

Schumaker, J. B., Deshler, D. D., Alley, G. R., Warner, M. M., \& Denton, P. H. (1982). Multipass: A learning strategy for improving reading comprehension. Learning Disability Quarterly, 5, 295-304.

Shanahan, T., Callison, K., Carriere, C., Duke, N. K., Pearson, P. D., Schatschneider, C., \& Torgesen, J. (2010). Improving reading comprehension in kindergarten through 3 rd grade: A practice guide (NCEE 2010-4038). Washington, DC: National Center for Education Evaluation and Regional Assistance, Institute of Education Sciences, US Department of Education. Retrieved from whatworks.ed.gov/publications/practiceguides.

Simmonds, E. P. M. (1992). The effects of teacher training and implementation of two methods for improving the comprehension skills of students with learning disabilities. Learning Disabilities Research and Practice, 7, 194-198.

Smith, P. L., \& Friend, M. (1986). Training learning disabled adolescents in a strategy for using text structure to aid recall of instructional prose. Learning Disabilities Research, 2, 38-44.

Taylor, L. K., Alber, S. R., \& Walker, D. W. (2002). The comparative effects of a modified self-questioning strategy and story mapping on the reading comprehension of elementary students with learning disabilities. Journal of Behavioral Education, 11, 69-87.

Taylor, B., Harris, L. A., Pearson, D. P., \& Garcia, G. (1995). Reading difficulties: Instruction and assessment (2nd ed.). New York: McGraw-Hill. 
Therrien, W. J., Wickstrom, K., \& Jones, K. (2006). Effect of a combined repeated reading and question generation intervention on reading achievement. Learning Disabilities Research and Practice, 21(2), 89-97.

Torgesen, J. K. (1982). The learning disabled child as an inactive learner. Topics in Learning and Learning Disabilities, 2, 45-52.

Torgesen, J. K. (1986). Computers and cognition in reading: A focus on decoding fluency. Exceptional Children, 53, 157-162.

van den Broek, P., Lynch, J. S., Naslund, J., Ievers-Landis, C. E., \& Verduin, K. (2003). The development of comprehension of main ideas in narratives: Evidence from the selection of titles. Journal of Educational Psychology, 95, 707-718.

Weaver, C. A., \& Kintsch, W. (1991/1996). Expository text. In R. Barr, M. L. Kamil, P. Mosenthal, \& P. D. Pearson (Eds.), Handbook of reading research (Vol. 2, pp. 230-245). Mahwah, NJ: Erlbaum.
Williams, J. P. (1988). Identifying main ideas: A basic aspect of reading comprehension. Topics in Language Disorders, 8(3), 1-13.

Williams, J. P. (2004). Teaching text structure to improve reading comprehension. In H. L. Swanson, K. R. Harris, \& S. Graham, (Eds.), Handbook of learning disabilities (pp. 293-305). New York: Guilford Press.

Winograd, P. N. (1984). Strategic difficulties in summarizing texts. Reading Research Quarterly, 19, 404-425.

Wittrock, M. C. (1992). Knowledge acquisition and comprehension. In M.C. Alkin (Ed.), Encyclopedia of educational research (6th ed.) (pp. 699-705). New York: Macmillan.

Wong, B. Y. L., \& Jones, W. (1982). Increasing metacomprehension in learning disabled and normally achieving students through selfquestioning training. Learning Disability Quarterly, 5, 228-240.

\section{PERMISSIONS AND COPYRIGHT}

All rights are reserved. No part of this publication may be reproduced, photocopied, faxed, stored in a retrieval system, or transmitted in any form or by any means, electronic, mechanical, recording or otherwise, without the prior written permission of the publisher.
Back issues are available for sale. Reproduction requires permission and payment of fees. It is illegal and a violation of federal copyright law to reproduce this publication without permission. Direct all inquiries to the permissions editor. 